University of Nebraska - Lincoln

DigitalCommons@University of Nebraska - Lincoln

Sociology Department, Faculty Publications

Sociology, Department of

$1-2004$

\title{
Early Sexual Abuse, Street Adversity, and Drug Use among Female Homeless and Runaway Adolescents in the Midwest
}

Xiaojin Chen

Tulane University, xchen1@tulane.edu

Kimberly A. Tyler

University of Nebraska-Lincoln, kim@ktresearch.net

Les B. Whitbeck

University of Nebraska-Lincoln, Iwhitbeck2@unl.edu

Dan R. Hoyt

University of Nebraska-Lincoln, dhoyt2@unl.edu

Follow this and additional works at: https://digitalcommons.unl.edu/sociologyfacpub

Part of the Sociology Commons

Chen, Xiaojin; Tyler, Kimberly A.; Whitbeck, Les B.; and Hoyt, Dan R., "Early Sexual Abuse, Street Adversity, and Drug Use among Female Homeless and Runaway Adolescents in the Midwest" (2004). Sociology Department, Faculty Publications. 66.

https://digitalcommons.unl.edu/sociologyfacpub/66

This Article is brought to you for free and open access by the Sociology, Department of at DigitalCommons@University of Nebraska - Lincoln. It has been accepted for inclusion in Sociology Department, Faculty Publications by an authorized administrator of DigitalCommons@University of Nebraska - Lincoln. 


\title{
Early Sexual Abuse, Street Adversity, and Drug Use among Female Homeless and Runaway Adolescents in the Midwest
}

\author{
Xiaojin Chen, Kimberly A.Tyler, Les B.Whitbeck, and Dan R. Hoyt
}

\begin{abstract}
Research on homeless and runaway adolescents has shown that this population is at high risk for illicit drug use. Though sexual abuse has been widely considered in the etiology of illicit drug use, we know less about how early sexual abuse affects young people's decisions to run away, to use drugs, and to engage in other deviant behavior on the streets. Based on interviews with 361 female homeless and runaway adolescents in four midwestern states, the current study revealed a high prevalence of drug use, especially use of cocaine among youths with sexual abuse histories. Path analyses showed that early sexual abuse indirectly affected drug use on the streets via running away at an earlier age, spending more time on the street, and use of deviant strategies to survive (e.g., affiliation with deviant peers, trading sex, and use of nonsexual deviant subsistence strategies).
\end{abstract}

Research on homeless and runaway adolescents has shown that this population is at high risk for illicit drug use (such as marijuana, speed, LSD, cocaine, inhalants, and mushrooms), and other deviant behavior (Greenblatt \& Robertson, 1993; Hagan \& McCarthy, 1997; Kipke, Montgomery, \& Mackenzie, 1993; Koopman, Rosario, \& Rotheram-Borus, 1994; Whitbeck \& Hoyt, 1999). Compared with the general adolescent population, rates

\footnotetext{
Xiaojin Chen, Ph.D., is an assistant professor in sociology at Tulane University in New Orleans, Louisiana. His current research interests include sociological methodology and deviance among homeless and runaway adolescents. Kimberly A. Tyler, Ph.D., is an assistant professor in sociology at the University of Nebraska-Lincoln. Her research interests include sexual risk taking behaviors, sexual abuse, and sexual victimization among homeless and runaway adolescents. Les B. Whitbeck is professor of sociology at the University of Nebraska-Lincoln. His research focus is adolescent risk and resilience. He is conducting a longitudinal study of homelessness and runaway adolescents. Dan R. Hoyt is a professor of sociology and head of the Bureau of Social Research at the University of NebraskaLincoln. His current research focuses on risk, deviance, and mental health among high risk populations.
} 
of drug use among homeless and runaway adolescents have been found to be substantially higher (Windle, 1989; Yates, Mackenzie, Pennbridge, \& Cohen, 1988). For example, Stiffman, Earls, Powell, and Robins (1987) reported the rate of drug use among homeless groups to be five times higher than their home-based peers (Stiffman et al.)

High rates of early childhood sexual abuse have also been found among homeless and runaway adolescents (McCormack, Janus, \& Burgess, 1986; Silbert \& Pines, 1981; Tyler, Hoyt, Whitbeck, \& Cauce, 2001). Sexual abuse has been widely considered in the etiology of illicit drug use among both the general population and among homeless and runaway adolescents (Finkelhor, Hotaling, Lewis, \& Smith, 1990; Rotheram-Borus et al., 1992; Widom \& Ames, 1994). Compared with other coping strategies, self-medication through illicit drug use may be more immediately effective and available to address the negative emotional effects associated with sexual abuse histories (Rutter, 1989). Although it has been established that homeless and runaway adolescents who have experienced sexual abuse have high rates of drug use, less is known about the indirect effects and their influence on drug use. In other words, does sexual abuse directly affect drug use or are the effects indirect through other street variables? The current study investigates the negative developmental effects of early sexual abuse on adolescent drug use, via running away, risky sexual activity, deviant subsistence strategies, and affiliation with deviant peers among 361 female homeless and runaway adolescents in the Midwest. Since the rate of sexual abuse is approximately two to three times higher among females compared to males (Finkelhor, 1993; McCormack et al.; Sedlak \& Broadhurst, 1996), females are the focus of this study.

\section{Childhood Sexual Abuse and Drug Use}

Research has shown that a large number of children, especially girls, suffer from sexual abuse each year (Finkelhor, 1984; Finkelhor, 1993; Finkelhor \& Browne, 1988; Finkelhor et al., 1990). For example, Finkelhor (1993) estimated that about $25 \%$ of girls and $10 \%$ of boys suffer victimization before age 18 years. These estimates, however, vary from study to study depending on the definition of sexual abuse and the sampling methods used by researchers. The most recent research shows a range from 20\% (Fleming, Mullen, \& Bammer, 1997) to 60\% (Peters, 1988).

Numerous clinical studies have found a positive association between childhood sexual abuse and substance use (Burgess \& Holmstrom, 1979; Rohsenow, Corbett, \& Devine, 1988; Straus, 1979). For example, Singer, Petchers and Hussey (1989) found that adolescents with a sexual abuse history were more likely to use cocaine, stimulants, and other drugs regularly than the matched group without a sexual abuse history. In a longitudinal 
study of juvenile detainees, Dembo et al. (1992) found early sexual victimization predicted use of marijuana/hashish. Whitmire and Harlow (1996) also found a positive association between child sexual abuse and hard drug use among college students. Large community sample surveys also provide additional evidence in support of this relationship (Burnam et al., 1988; Finkelhor et al, 1990; Kilpatrick, Edmunds, \& Seymour, 1992; Stein, Golding, Siegei, Burnham, \& Sorenson, 1988; Winfield, George, Swartz, \& Blazer, 1990). Adolescents with histories of sexual abuse were more likely to be multiple substance users (Harrison, Fulkerson, \& Beebe, 1997). In addition, similar to the general population, females with a history of childhood sexual abuse were also at higher risk of substance use and abuse (Browne \& Finkelhor, 1986).

\section{Runaway and Homeless Youth}

It has been well documented that the rates of childhood sexual abuse are much higher among runaway and homeless adolescents (Janus, Burgess, \& McCormack, 1987; McCormack et al., 1986). Compared with their home-based peers, homeless and runaway adolescents are more likely to come from dysfunctional families, for example, families characterized by physical abuse, sexual exploitation, neglect, and abandonment (Bucy \& Obolensky, 1990). Jencks (1994) found that 70\% of homeless adolescents were physically or sexually abused while they were at home. Considering the high rates of sexual abuse, it is no surprise that many runaway adolescents rank sexual abuse as one of the most important reasons for running away (Fleming, 1991; Garbarino, Schellenbach, \& Sebes, 1987). Similar to the general adolescent population, female runaway and homeless adolescents reported higher rates of childhood sexual abuse compared to their male counterparts (Finkelhor, 1993). For example, McCormack et al. (1986) showed that $73 \%$ of female homeless and runaways suffered sexual abuse, while $38 \%$ of males were sexually abused while at home.

High rates of substance abuse, especially drag and alcohol use, have been found among homeless and runaway youth (Hagan \& McCarthy, 1997; Whitbeck \& Hoyt, 1999). Kipke and colleagues found that $71 \%$ of homeless adolescents in Southern California met DSM-III criteria for substance abuse (Kipke, Simon, Montgomery, Unger, \& Iverson, 1997). Other studies also reported elevated levels of alcohol and drug use among runaway and homeless adolescents (Koopman et al., 1994). Compared with their home-based peers, drug and alcohol use was considerably higher among the homeless and runaway adolescent population (Stiffman et al., 1987; Windle, 1989; Yates et al., 1988). For example, Stiffman and colleagues (1987) reported the rate of drug use among homeless groups was five times higher than their home-based peers. 


\section{Theoretical Model}

The current study proposes a risk amplification model, developed by Whitbeck and colleagues (1999), to examine the negative effects of early sexual abuse on illicit drug use on the street among female homeless and runaway adolescents. Patterson has argued that coercive/abusive families provide "basic training" (Patterson, Dishion, \& Bank, 1984) for antisocial behavior to adolescents due to the continuous failure on the parts of parents to use effective discipline techniques to control coercive exchanges between family members. Drawn from Patterson's (1982) social interaction theory and life course developmental theory (Elder, 1998), the risk amplification model suggests that homeless adolescents have their "basic training" in their coercive/abusive families and will carry this interaction pattern into the street, thereby setting in motion a negative chain of events. Specifically, adolescents with a sexual abuse history will be more likely to run away early, spend more time on the street, and affiliate with antisocial friends. In turn, street experiences will lead these adolescents to use deviant strategies to survive, which will in turn increase their drug use (see Figure 1). A fully recursive model (i.e., all possible paths are hypothesized, with the exception of reciprocal paths) was hypothesized to examine the cumulative effects of early sexual abuse on drug use on the street. Age and race were controlled in this model. We expected older respondents to have more opportunities to spend time on the street and use drugs than the younger respondents. Race is also controlled since nonWhites in the general population use less alcohol and drugs (Barnes \& Welte, 1986; Johnston, O’Malley, \& Bachman, 1999; Maddahian, Newcomb, \& Bentler, 1988), and we expected a similar pattern among homeless and runaway adolescents.

Figure 1 shows the theoretical model illustrating the specific mechanism through which interactional and behavioral continuities result in increased drug use for female homeless and runaway adolescents. In the model, it was hypothesized that precocious independence, which is the premature absence of direct adult supervision, control, and influence, would exacerbate the effects of early sexual abuse on street risk factors, thereby increasing drug use. Studies on runaway and homeless populations have shown that physical and/or sexual abuse at home was one of the most important reasons for running away (Fleming, 1991; Garbarino et al., 1987). Since most childhood sexual abuse occurs between eight and 12 years of age (Finkelhor, 1984), we expected that youth with an early sexual abuse history would run away from home at an early age (Arrow A). Several studies have found a positive association between family physical/sexual abuse and number of times adolescents run away and the total time adolescents spend on the streets (Kufeldt \& Nimmo, 1987; Tyler, Hoyt, Whitbeck, \& Cauce, 2001; Whitbeck \& Simons, 1990). Based on these results, we hypoth- 


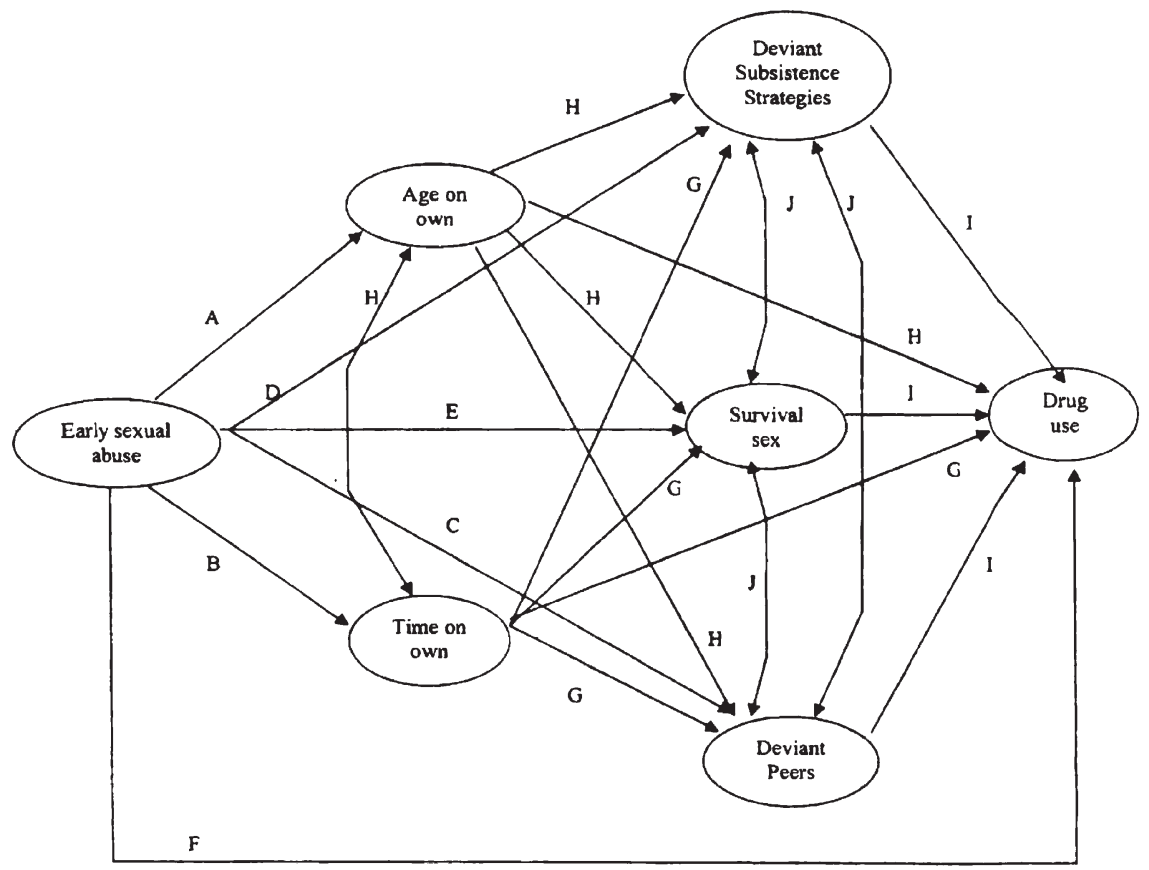

Figure 1. Hypothesized Model. (Age and race are controlled in this model.)

esized a positive association between a history of early sexual abuse and time on own (Arrow B). Numerous studies have found that abusive family backgrounds lead adolescents to affiliate more with nontraditional peers (Patterson, Debaryshe, \& Ramaey, 1989; Whitbeck \& Simons, 1990; Tyler et al., 2001); therefore, it was hypothesized that a history of early sexual abuse would be positively associated with affiliation with deviant peers (Arrow C). A number of studies have found a positive association between child sexual abuse and use of deviant subsistence strategies, including survival sex (Browne \& Finkelhor, 1986; McMorris, Tyler, Whitbeck, \& Hoyt, 2002; Silbert \& Pines, 1981; Simons \& Whitbeck, 1991). Miller (1986) suggested that young females who had sexual abuse histories learned to employ the "emotional distancing" tactic while serving their tricks. Based on these findings, females with a sexual abuse history were predicted to engage in deviant subsistence strategies (Arrow D) and trading sex for food, money, and shelter (Arrow E). Finally, direct effects were tested between early sexual abuse and drug use while on the street (Arrow F) since some studies 
have suggested that physical/sexual abuse at home increases the probability of homeless and runaway adolescents using drugs (Baron, 1999; Johnson, Aschkenasy, Hervers, \& Gillenwater, 1996).

Once exposed on the streets, the lack of legitimate means to support themselves lead these youths to associate with similarly situated peers (Kipke et al., 1997) and to engage in problem behavior, such as stealing, trading sex, drinking, and using drugs (Tyler, Whitbeck, Hoyt, \& Yoder, 2000; Whitbeck \& Hoyt, 1999). Thus, a positive association was hypothesized between spending time on the street and deviant subsistence strategies, trading sex, affiliation with deviant peers, and using drugs (Arrows $\mathrm{G}$ ). Adolescents running at an early age also tend to run away multiple times, thus having more opportunity to stay on the street and make antisocial friends (Whitbeck \& Hoyt, 1999). In turn, we hypothesized that the younger the adolescents were when they ran away from home, the more likely they would spend more time on the street, affiliate with antisocial friends, engage in survival sex, participate in deviant subsistence strategies, and use drugs on the street (Arrows H). Finally, because research has found that substance use among homeless adolescents was highly associated with delinquency and aggressive behavior (MacLean, Paradise, \& Cauce, 1999), we test for associations between deviant peers, survival sex, and deviant subsistence strategies on drug use (Arrows I). We also test the association between affiliation with deviant peers, survival sex, and use of deviant subsistence strategies (Arrows J) since these three are highly correlated (Whitbeck \& Hoyt, 1999).

\section{Method}

Sample

Six hundred and two homeless and runaway adolescents from five Midwestern cities (St. Louis and Kansas City, Missouri; Wichita, Kansas; Lincoln, Nebraska; and Des Moines, Iowa) were interviewed. Of these, only the females $(\mathrm{N}=361)$ were used in the analysis. Young people were interviewed using a systematic sampling strategy that maximized locating homeless and runaway youth. This approach was used since it is not possible to randomly sample homeless populations (Wright, Allen, \& Devine, 1995). This strategy employed both street intercepts and locale interviewing. In this study, homeless adolescents were interviewed by outreach workers who had considerable experience in interviewing and interacting with these young people and who were very familiar and trusted by them. Interviews occurred on the streets, in shelters, and in drop-in centers. Before the interview, participants were asked to sign a consent form, which included a statement explaining the mandatory reporting of child abuse and a statement of our responsibility to offer help. The average interview 
lasted about 1 1/2 hours. A snack was provided during the interview, and each respondent received $\$ 15$ for participating in the study.

Due to the reimbursement rates and the familiarity of the outreach workers with homeless and runaway adolescents, the overall average response rate was $93 \%$ (ranged from $71.7 \%$ to $100 \%$ ) across different cities in these four states.

In terms of demographics (Table 1), among the 361 females who were interviewed, the majority was White (63\%); $21 \%$ were African American; $4 \%$ were Hispanic; and 14\% were Native Indian, Asian, or "other." These young women ranged in age from 12 to 22 years old, with a mean age of 16 years. Grade completed in school ranged from fifth grade to two years in college, with a mean of ninth grade. Six percent of these female adolescents did not complete or just completed elementary education; about $45 \%$ did not complete or just completed junior high school education; and only $3 \%$ finished high school or more education.

\section{Measures}

\section{Early Sexual Abuse}

The early sexual abuse scale consisted of Whitbeck and Simons's (1990) measures of sexual abuse that adolescents had experienced while living at home. Respondents were asked how often a parent, a foster parent, adult relatives, or any adult who was supposed to be taking care of the respondent had made verbal requests for sexual activity, or how often they made the respondents do something sexually or "messed around" with them sexually. Response categories for the scale ranged from 1 (never) to 4 (many times). These two items were highly correlated $(r=.78)$. Among those adolescents who had been asked verbally, $88.7 \%$ of them had been forced to have sex with adults. Similarly, among those who had been forced to have sex, $76.4 \%$ had been asked verbally by the adults. Because of the overlap between these two items, a count procedure was performed to create the composite measure of early sexual abuse. Due to the skewness of this measure, this composite measure was dichotomized $(0=$ never, and $1=$ at least once).

To further understand the onset of sexual abuse, respondents were asked how old they were when the first time this happened if they answered yes to any of these two items. The average age that adolescents were asked verbally to have sex was 9.3 years old and 11.9 years old for being forced to have sex. The result of this sample was consistent with Finkelhor's (1984) research that most early sexual abuse occurred between eight and 12 years old.

\section{Age on Own}

Age on own was a single indicator that asked how old the respondents were when they first ran away from home. The average age for running away was 13.55 years old. 
Table 1. Demographics among Female Homeless and Runaway Adolescents in the Midwest

\begin{tabular}{|c|c|c|}
\hline & Frequency & Percentage (\%) \\
\hline \multicolumn{3}{|l|}{$\overline{\text { Age }}$} \\
\hline 13 and below & 32 & 8.9 \\
\hline 14 & 44 & 12.2 \\
\hline 15 & 59 & 16.3 \\
\hline 16 & 91 & 25.2 \\
\hline 17 & 62 & 17.2 \\
\hline 18 and above & 73 & 20.2 \\
\hline \multicolumn{3}{|l|}{ Race/Ethnicity } \\
\hline White & 229 & 63.4 \\
\hline Non-Hispanic Black & 77 & 21.3 \\
\hline Hispanic & 14 & 3.9 \\
\hline Others & 41 & 13.8 \\
\hline \multicolumn{3}{|l|}{ Education } \\
\hline 6th grade and below & 21 & 5.8 \\
\hline 7 th grade & 51 & 14.1 \\
\hline 8 th grade & 89 & 24.7 \\
\hline 9th grade & 77 & 21.3 \\
\hline 10th grade & 74 & 20.5 \\
\hline 11th grade & 38 & 10.6 \\
\hline 12th grade and above & 11 & 3.0 \\
\hline
\end{tabular}

\section{Time On Own}

Time on own was measured by the total amount of time that these female adolescents had been either on the street or in unsupervised living arrangements (e.g., living with friends, having an apartment) since living away from home. The average length of time for these youths was 181.89 days. Due to the high skewness of this measurement, a logarithm transformation was performed.

\section{Survival Sex}

Survival sex was a two-item scale that asked whether female adolescents had ever traded sex for food, shelter, money, or drugs (Whitbeck \& Simons, 1990). The response categories were 1 (yes) and 2 (no). After recoding the categories into 1 (yes) and 0 (no), a sum procedure was performed to create the composite measure. Due to the skewness of this measurement, this variable was dichotomized into 0 (never traded sex) and 1 (traded sex at least once). The correlation between these two items was 0.56 . 


\section{Deviant Peers}

Affiliation with deviant peers was measured using 13 items. Respondents were asked whether they had close friends who had run away; sold drugs; used drugs; been suspended from school; dropped out of school; shoplifted; broke in a house or store; took money from someone else; sold sex for food, drugs, money, or shelter; been arrested; threatened someone with a weapon; and assaulted someone with a weapon (adapted from Whitbeck \& Simons, 1990). Response categories ranged from 1 (yes) to 2 (no). After recoding every item so that $1=y e s$, and $0=$ no, the sum procedure was performed to create a composite measurement. A higher value indicated more deviant close friends. Cronbach's alpha (a) for deviant peers affiliation was 0.89 .

\section{Deviant Subsistence Strategies}

Deviant subsistence strategies was measured using four items that focused on different tactics which adolescents may have used in order to survive since being on the streets (adapted from Whitbeck \& Simons, 1990). Respondents were asked to indicate whether they had ever taken money or something else from someone, broken into a house or store, stolen or shoplifted, and panhandled or spare changed. A sum procedure was performed to create the composite measurement and delete missing cases. A higher value means higher frequency of use of deviant subsistence strategies. Cronbach's alpha (a) for deviant subsistence strategies was 0.68.

\section{Drug Use}

Drug use was measured by asking how often respondents smoked marijuana, crank, other amphetamines, cocaine, opiates, hallucinogens, tranquilizers, barbiturates, and inhalants in the last 12 months. Response categories ranged from 0 (never) to 6 (daily). The nine items were summed to create a composite measure for drug use. Previous research attests to the validity and reliability of such scales (Elliott, Huizinga, \& Ageton, 1985).

Age and race were controlled for in the model. Race was coded 0 for non-Whites and 1 for Whites, and age ranged from 12 to 22 years with a mean of 16 years.

\section{Results}

Overall, 32\% of females in this study reported that they had been sexually abused by adult caretakers while they stayed with their families. About one fourth $(23.7 \%)$ reported that a parent/caretaker requested sex, and $22 \%$ of these youths had been forced to have sex. One out of 10 reported they had been forced to have sex a few times or more. In terms of race, $27 \%$ of non-White female adolescents reported that they had been sexually abused 
by adult caretakers, as did 35\% of White adolescents; however, there was no significant difference between these two groups. There was no age difference between sexually abused adolescents and those who had not been sexually abused.

Our results indicated that drug use was highly prevalent among these adolescents. Overall, more than two thirds (69.3\%) of females had used at least one kind of drug in the last 12 months. The prevalence of drug use was almost equal between females with a sexual abuse history and those without, $70.0 \%$ versus $68.7 \%$, respectively. About one third $(34.4 \%)$ of these youths used multiple drugs, and there were significant differences between females with a sexual abuse history and those without. Among those who used at least one type of illicit drug in the last 12 months, $59.7 \%$ of young women with a sexual abuse history used multiple drugs; the rate for those without such a history was $44.3 \%$.

Table 2 shows the prevalence of each single drug used among female homeless and runaway adolescents when they were on the streets. Marijuana, amphetamines (not including crank), and hallucinogens were the most frequently used illicit drugs among these street youths. Almost two thirds $(64.9 \%)$ used marijuana, more than one fifth $(22.4 \%)$ used amphetamines (not including crank), and one fifth (19.6\%) used hallucinogens during the last 12 months. Table 2 also shows the preference of drug use among those with sexual abuse histories. Females with a sexual abuse history were two times more likely to use cocaine $(19.6 \%)$ than those who were not sexually abused. In addition, there were also significant differences on use of hallucinogens, tranquilizers, barbiturates, and inhalants between these two groups. Those with a sexual abuse history reported drug use rates 1.5 to 2 times higher than those who were not sexually abused. Reported use of marijuana and amphetamines, however, showed no significant difference between these two groups.

Descriptive statistics and Pearson correlation coefficients for the variables used in the present analysis are presented in Table 3. After listwise deletion of missing cases, the present analysis comprised 347 youths. At the bivariate level, early sexual abuse was significantly associated with age of first running away $(r=-.21)$, spending time on the street $(r=.12)$, affiliation with deviant peers $(r=.15)$, and use of drugs $(r=.13)$. Drug use was significantly associated with age of first running away $(r=-.14)$ and spending time on the street $(r=.19)$. Drug use, predictably, was strongly associated with use of deviant subsistence strategies $(r=.29)$; trading sex for food, money, and shelter $(r=.34)$; and affiliation with deviant peers $(r=.44)$.

\section{Path Model of Early Sexual Abuse and Later Drug Use}

The fully recursive path model was tested. To obtain the most parsimonious model, a series of nested models, which constrained some of the non- 
Table 2. Drug Use among Female Homeless and Runaway Adolescents $(N=356)$

\begin{tabular}{lccc}
\hline & $\begin{array}{c}\text { Not sexually abused } \\
(\%)\end{array}$ & $\begin{array}{c}\text { Sexually Abused } \\
(\%)\end{array}$ & $\begin{array}{c}\text { Total } \\
(\%)\end{array}$ \\
\hline Marijuana & 64.5 & 65.0 & 64.9 \\
Crank (Crank with & 10.8 & 17.0 & 12.8 \\
$\quad$ amphetamines) & & & \\
Other amphetamines & 20.8 & 25.9 & 22.4 \\
Cocaine & $10.0^{* *}$ & 19.6 & 13.1 \\
Opiates & 38.0 & 5.4 & 4.3 \\
Hallucinogens & $17.1^{*}$ & 25.0 & 19.6 \\
Tranquilizers & $5.0^{*}$ & 9.8 & 6.5 \\
Barbiturates & $5.0^{*}$ & 10.7 & 6.8 \\
Inhalants & $10.0^{*}$ & 17.9 & 12.5 \\
\hline$* p<0.05$ between females with nonsexual abuse history and sexually abused (one tail test) \\
** $p<0.01$ between females with nonsexual abuse history and sexually abused (one tail test)
\end{tabular}

Table 3. Bivariate Correlation Matrix $(N=347)$

\begin{tabular}{lccccccccc}
\hline & 1 & 2 & 3 & 4 & 5 & 6 & 7 & 8 & 9 \\
\hline 1 Age & 1.00 & & & & & & & & \\
2 Race & -0.02 & 1.00 & & & & & & & \\
3 Early sexual abuse & 0.04 & 0.07 & 1.00 & & & & & & \\
4 Age on own & $0.34^{* *}-0.07$ & $-0.21^{* *}$ & 1.00 & & & & & \\
5 Time on own (log) & $0.39^{* *}$ & 0.00 & $0.12^{* *}-0.17^{* *} 1.00$ & & & & \\
6 Subsistence strategy & -0.09 & -0.05 & 0.10 & $-0.11^{*}$ & $0.11^{*}$ & 1.00 & & & \\
7 Survival sex & 0.05 & 0.07 & 0.10 & $-0.13^{*}$ & $0.13^{*}$ & $0.25^{* *}$ & 1.00 & & \\
8 Deviant peers & $0.15^{* *}$ & 0.10 & $0.15^{* *}-0.10$ & $0.24^{*}$ & $0.34^{* *}$ & $0.24^{* *}$ & 1.00 & \\
9 Drug use & 0.04 & 0.06 & $0.13^{*}$ & $-0.14^{*}$ & $0.19^{*}$ & $0.29^{* *}$ & $0.34^{* *}$ & $0.44^{* *}$ & 1.00 \\
Mean & 16.02 & 0.65 & 0.32 & 13.54 & 3.90 & 0.49 & 0.06 & 7.00 & 4.39 \\
SD & 1.81 & 0.48 & 0.47 & 2.47 & 1.83 & 0.93 & 0.24 & 3.69 & 5.95 \\
\hline
\end{tabular}

${ }^{*} p<.05 * * p<.01$

signifcant paths in the full model to zero, were fitted to the data. The difference between the fully recursive model and the more restrained models was tested by using the likelihood ratio test. The results of the most parsimonious model were presented in Figure 2. Because some of the variables were dichotomous, this model was estimated using the unweighted least squares (ULS) procedure in LISREL 8 (Joreskog \& Sorbom, 1993). Overall, the reduced path model fitted the data very well. The chi-square difference was statistically nonsignificant $\left(\chi^{2}=12.71 ; d f=12 ; p=.39\right)$ compared with the hypothesized fully recursive model. The goodness of fit index was 1.00 and the adjusted goodness of fit index was .99. The root mean square of ap- 
proximation was 0.01. About one third of the variance of drug use among these female homeless and runaway adolescents was explained by this path model $\left(R^{2}=.33\right)$.

The results were consistent with findings in the bivariate analysis. Those with early sexual abuse histories were more likely to run away from home at an earlier age $(\beta=-.21)$ and spend more time on the street $(\beta=.12)$. It is noteworthy that youths with early sexual abuse histories were also more likely to trade sex for food, money, shelter, and drugs $(\beta=.12)$ than those who did not report early sexual abuse. Early life experience on the street increased the probability of connecting with deviant peers and engaging in deviant behavior. Specifically, the greater the length of time on their own, the greater the likelihood of adolescents hanging out with antisocial friends $(\beta=.15)$; trading sex for food, money, shelter, drugs $(\beta=.20)$; and engaging in other deviant subsistence strategies to survive on the street $(\beta=.10)$. Youths who reported running away at an earlier age were more likely to trade sex $(\beta=-.19)$, engage in deviant subsistence strategies $(\beta=-.13)$, and connect with other antisocial friends $(\beta=-.17)$. The three indicators of street experience, as expected, were highly correlated with each other. Affiliation with deviant peers was highly correlated with both sexual activities $(\beta=$ .29) and use of deviant strategies to survive on the street $(\beta=.37)$. Trading sex for survival was also moderately correlated with use of deviant strategies on the street $(\beta=.17)$. As predicted, associating with deviant friends, trading sex, and engaging in deviant subsistence strategies were strongly related to adolescent drug use $(\beta=.31, \beta=.24, \beta=.17$, respectively).

Controlling for the effects of age (not shown) revealed that older respondents were more likely to have run away from home at later ages, but they were also more likely to have been on the streets for a longer time. In terms of race, whites were more likely to run away from home at an earlier age, and they were also more likely to use drugs.

The decomposition of effects of the independent variables on the dependent variables (Joreskog \& Sorbom, 1993) in Table 4 suggests several themes. First, the effects of early sexual abuse, age of first running away, and time spent on the street on illicit drug use were indirect through other components in the model. The effects of early sexual abuse were entirely mediated by the intervening variables. Second, the effects of early sexual abuse on engaging in survival sex were fairly evenly divided between a direct and an indirect effect. Early sexual abuse directly and indirectly impacted youths' use of survival sex through running away at an early age and staying out on the streets for longer time periods. Third, as expected, the strongest direct path to adolescent drug use occurred for the more proximal deviant behaviors engaged on the street: associating with antisocial peers, engaging in deviant subsistence strategies, and trading sex for survival on the street. 


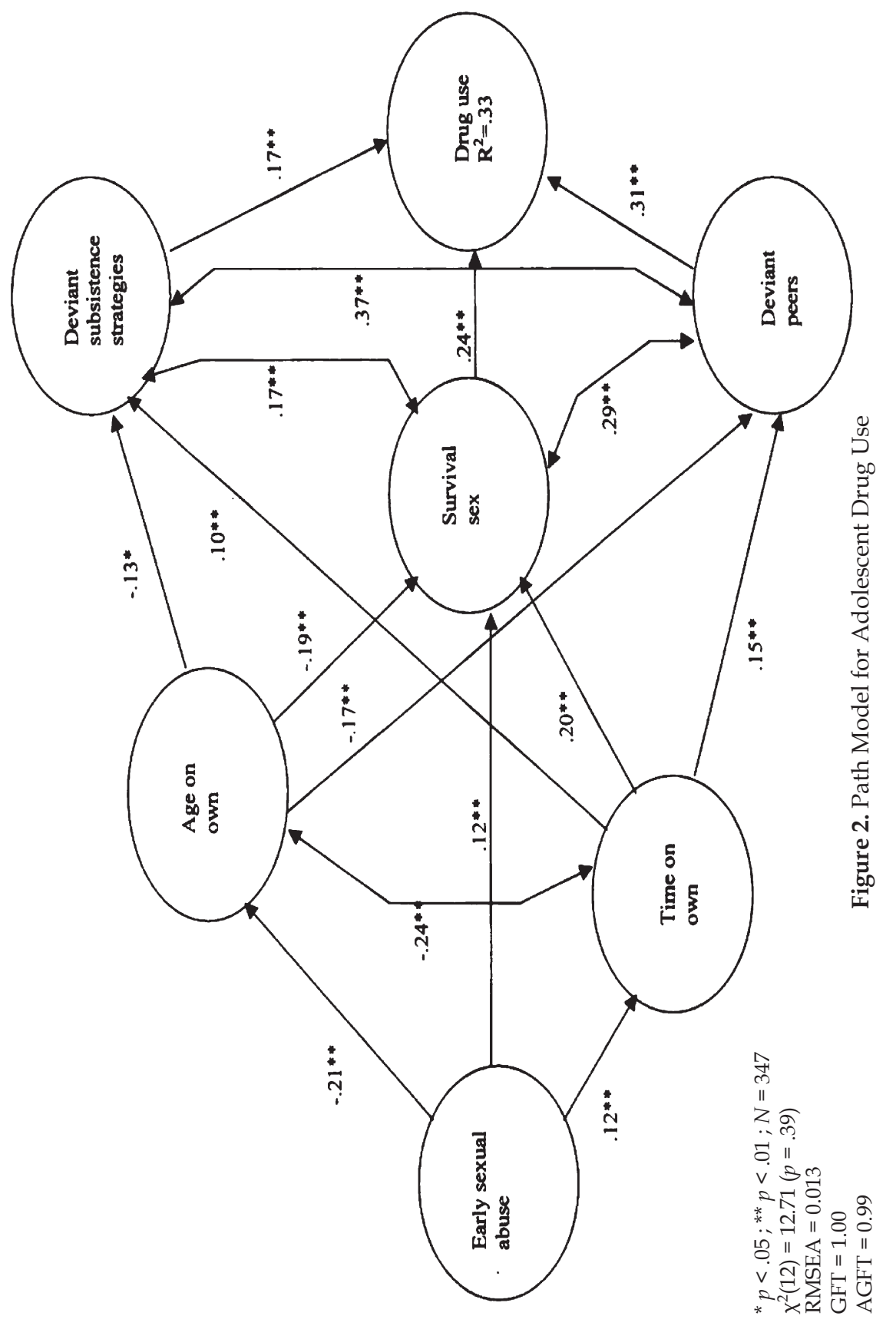


Table 4. Decomposition of Effects for Path Model

\begin{tabular}{|c|c|c|c|c|c|c|}
\hline & $\begin{array}{c}\text { Age } \\
\text { on own }\end{array}$ & $\begin{array}{l}\text { Time } \\
\text { on own }\end{array}$ & $\begin{array}{c}\text { Deviant } \\
\text { subsistence } \\
\text { strategy }\end{array}$ & $\begin{array}{l}\text { Survival } \\
\text { sex }\end{array}$ & $\begin{array}{c}\text { Deviant } \\
\text { peers }\end{array}$ & Drug use \\
\hline \multicolumn{7}{|c|}{ Early sexual abuse } \\
\hline Direct & $-.21^{* *}$ & $.13^{* *}$ & -- & $.12^{* *}$ & -- & -- \\
\hline Indirect & -- & -- & $.04^{* *}$ & $.07^{* *}$ & $.05^{* *}$ & $.07^{* *}$ \\
\hline Total & $-.21^{* *}$ & $.13^{* *}$ & $.04^{* *}$ & $.19^{* *}$ & $.05^{* *}$ & $.07^{* *}$ \\
\hline \multicolumn{7}{|l|}{ Age on own } \\
\hline Direct & & & $-.13^{* *}$ & $-.19 * *$ & $-.17^{* *}$ & -- \\
\hline Indirect & & & -- & -- & -- & $.12^{* *}$ \\
\hline Total & & & $-.13^{* *}$ & $-.19 * *$ & $-.17^{* *}$ & $.12^{* *}$ \\
\hline \multicolumn{7}{|c|}{ Time on own } \\
\hline Direct & & & $.10^{* *}$ & $.20 * *$ & $.15^{* *}$ & -- \\
\hline Indirect & & & -- & -- & -- & $.11^{* *}$ \\
\hline Total & & & $.10^{* *}$ & $.20^{* *}$ & $.15^{* *}$ & $.11^{* *}$ \\
\hline \multicolumn{7}{|c|}{ Deviant subsistence strategy } \\
\hline Direct & & & & & & $.17^{* *}$ \\
\hline Indirect & & & & & & -- \\
\hline Total & & & & & & $.17^{* *}$ \\
\hline \multicolumn{7}{|c|}{ Survival sex } \\
\hline Direct & & & & & & $.24^{* *}$ \\
\hline Indirect & & & & & & -- \\
\hline Total & & & & & & $.24^{* *}$ \\
\hline \multicolumn{7}{|c|}{ Deviant peers } \\
\hline Direct & & & & & & $.31^{* *}$ \\
\hline Indirect & & & & & & -- \\
\hline Total & & & & & & $.31^{* *}$ \\
\hline
\end{tabular}

\section{Discussion and Conclusion}

Consistent with previous research (Hagan \& McCarthy, 1997; Whitbeck \& Hoyt, 1999), this study found high prevalence rates of drug use, especially marijuana use among female runaway and homeless adolescents. The negative effects of early sexual abuse on later drug use were supported. Though the prevalence of drug use was similar between female adolescents with and without sexual abuse histories, we found that 
female adolescents with sexual abuse histories were more likely to be multiple drug users. In addition, abused females were more likely to use certain drugs, especially cocaine, which were hypothesized to reduce the negative emotional effects associated with early sexual abuse (Beitchman et al., 1992; Browne \& Finklehor, 1986). The preference for cocaine among adolescents with sexual abuse histories is consistent with previous research (Kilpatrick et al., 1992). Female adolescents with sexual abuse histories were also more likely to use hallucinogens, tranquilizers, barbiturates, and inhalants.

This study also tested direct and indirect effects models of relationships between early sexual abuse and drug use on the streets. The findings provide support for a risk amplification approach to explaining drug use among female runaway and homeless adolescents. First, the model indicates that early sexual abuse directly increases the probability of running away at an earlier age and spending more time on the streets. As suggested by the literature, a direct effect is also found between early sexual abuse and risky sexual activities among these youth (Tyler et al., 2001). Consistent with "cumulative continuity" theory proposed by Caspi, Bern, and Elder (1989) and Patterson's social interaction theory $(1982,1989)$, the negative effects of sexual abuse at home are amplified while these youths are on the streets. Adverse environment and lack of resources force these young people to connect with others who are similar to themselves and engage in deviant subsistence strategies, including drug use. Second, consistent with a risk amplification approach, though we found significant associations between early sexual abuse and later drug use on the streets, all of the effects were mediated through more proximal deviant behaviors while on the streets and affiliation with antisocial peers. In addition, drag use is mostly explained by these variables, which are directly or indirectly affected by early sexual abuse.

It should be noted that there are some limitations for this study. First, because it is almost impossible to randomly sample runaway and homeless adolescent populations, these data are not based on a probability sample. The data were collected from multiple sites in the Midwest, however, which increased the reliability and generalizability of these data. Second, cross-sectional data are used in this study, which may bring questions to the causal relationship hypothesized in the path model. For example, the debate regarding the causal relationship between deviant subsistence strategies and drug use in prior literature suggests that drug use may also increase use of delinquent activities (Kaplan, 1988). Though decomposition of effects suggests that street variables mediate the effects of sexual abuse on drug use, longitudinal data are needed to lend support to this causal argument. Third, our measures are based on adolescents' self-reported data, which might be a source of systematic bias. Most of the interviewers, however, believed if there was any systematic reporting bias, the direction was 
underreporting rather than overreporting negative experiences and behaviors (Whitbeck \& Hoyt, 1999). Finally, some of our measurements consisted of single items or two items, which may affect the reliability of these measurements.

Despite these limitations, the results provide important information regarding the effects of early sexual abuse on drug use in this high-risk population. First, though high prevalence of drug use, especially marijuana use, is interpreted as a way of socializing with others and getting by while on the streets (Whitbeck \& Hoyt, 1999), drug use, especially cocaine use among those with sexual abuse histories, may also be adopted as a coping mechanism to reduce emotional distress related to earlier abuse. Second, different from previous research, we found the prevalence of drug use was similar between the groups with and without sexual abuse histories; however, runaway and homeless adolescents with sexual abuse histories were more likely to be multiple drug users and headed towards use of harder drugs. Use of multiple drugs and precocious independence on the street would further push these youth from their traditional social network and connect them with same-aged peers who are in similar situations, which, in turn, may increase their chances of being chronic drug users and eventually homeless adults. Third, addiction to multiple drugs may bring these youth into conflict with the law, not only because possession of drugs is itself illegal, but also because drug use may stimulate other illegal activities.

In summary, early sexual abuse sets in motion a negative chain of events where adolescents who are victimized at home are often forced into precocious independence, which leads to their association with similarly situated peers and their participation in deviant subsistence strategies and other high-risk behaviors including drug use. Their continued involvement in high-risk behaviors may lead some of these young people to become chronic drug users and perhaps, eventually, part of the adult homeless population.

\section{Acknowledgments}

This research was supported by a grant from the National Institute of Mental Health (MH50140), with Les B. Whitbeck as the principal investigator.

Address correspondence to the first author, Xiaojin Chen, Department of Sociology, 220 Newcomb Hall, Tulane University, New Orleans, LA 70118; Email: xchen1@tulane.edu 


\section{References}

Barnes, G.M., \& Welte, J. W.

1986 Adolescent alcohol abuse: Subgroup differences and relationship to other problem behaviors. Journal of Adolescent Research, 1, 79-94.

Baron, S. W.

1999 Street youths and substance use: The role of background, street lifestyle, and economic factors. Youth and Society, 31 (1), 3-26.

Beitchman, J. H., Zucker, K., Hood, J. E., Dacosta, G. A., Akman, D., \& Cassavia, E.

1992 A review of the long-term effects of child sexual abuse. Child Abuse $\mathcal{E} \mathrm{Ne}$ glect, 16, 101-118.

Browne, A., \& Finkelhor, D.

1986 Impact of childhood sexual abuse: A review of the research. Psychological Bulletin, 99, 66-77.

Bucy, J., \& Obolensky, N.

1990 Runaway and homeless youths. In M. Rotheram-Borus, J. Bradley, \& N. Obolensky (Eds.), Planning to live: Evaluation and treating suicidal teens in community settings (pp. 333-353). Tulsa: University of Oklahoma Press.

Burgess, A. W., \& Holmstrom, L. I.

1979 Rape: Crisis and recovery. Bowie, MD: Brady.

Burnam, M. A., Stein, J. A., Golding, J. M., Siegel, J. M., Sorenson, S. B., Forsythe, A.B., \& Telles, C. A.

1988 Sexual assault and mental disorders in a community population. Journal of Consulting and Clinical Psychology, 56, 83-850.

Capsi, A., Bem, D. J., \& Elder, G.H.

1989 Continuities and consequences of interactional styles across the life course. Journal of Personality, 57, 375-406.

Dembo, R., Williams, L., Schmeidler, J., Berry, E., Wothke, W., Getreu, A., Wish, E., \& Christensen, C.

1992 A structural model examining the relationship between physical child abuse, sexual victimization, and marijuana/hashish use in delinquent youth: A longitudinal study. Violence and Victims, 7 (1), 41-61.

Elder, G.

1998 Life course and human development. In R.M. Lerner (Ed.), Handbook of child psychology: Vol. 1. Theoretical models of human development (pp. 939991). New York: John Wiley \& Sons, 939-991.

Elliott, D. S., Huizinga, D., \& Ageton, S. S.

1985 Explaining delinquency and drug use. Beverly Hills, CA: Sage.

Finkelhor, D.

1984 Child sexual abuse: New theory and research. New York: Free Press.

Finkelhor, D.

1993 Epidemiological factors in the clinical identification of child sexual abuse. The Future of Children, 4, 31-53. 
Finkelhor, D., \& Browne, A.

1988 Child sexual abuse: a review and conceptualization. In C.T. Hotaling, D. Finkelhor, H. T. Kirkpatrick, \& M. A. Straus (Eds.), Family abuse and its consequences: New directions in research (pp. 270-284). Newbury Park, CA: Sage.

Finkelhor, D., Hotaling, G. T., Lewis, I. A., \& Smith, C.

1990 Sexual abuse in a national survey of adult men and women: Prevalence, characteristics and risk factors. Child Abuse \& Neglect, 14, 19-28.

Fleming, J. M.

1991 Needs assessment of runaway youths and formulation of an assistance program. Unpublished thesis, Department of Sociology, Iowa State University.

Fleming, J., Mullen, P., \& Bammer, G.

1997 A study of potential risk factors for sexual abuse in childhood. Child Abuse E Neglect, 21, 49-58.

Garbarino, H., Schellenbach, C. J., \& Seber, J.

1987 Troubled youth, troubled families. New York: Alpine De Gruyter.

Greenblatt, M., \& Robertson, M. J.

1993 Life-style, adaptive strategies, and sexual behaviors of homeless adolescents. Hospital and Community Psychiatry, 44, 1177-1180.

Hagan, J., \& McCarthy, B.

1997 Mean streets: Youth crime and homelessness. New York: Cambridge University Press.

Harrison, P. A., Fulkerson, J. A., \& Beebe, T. J.

1997 Multiple substance use among adolescent physical and sexual abuse victims. Child Abuse \& Neglect, 21, 529-539.

Janus, M., Burgess, A., \& McCormack, A.

1987 Histories of sexual abuse in adolescent male runaways. Adolescence, 22, 405-417.

Jencks, C.

1994 The homeless. Cambridge, MA: Harvard University Press.

Johnston, L.D., O’Malley, P.M., \& Bachman, J.G.

1999 National survey results on drug use from the monitoring the future study, 19751998. Washington, D.C.: U.S. Department of Health and Human Services.

Johnson, T. P., Aschkenasy, J. R., Herbers, M. R., \& Gillwnwater, S. A.

1996 Self-reported risk factors for AIDS among homeless youth. AIDS Education and Prevention, 8( 4), 308-322.

Joreskog, K. G., \& Sorbom, D.

1993 LISREL 8: User's reference guide. Chicago, IL: Scientific Software.

Kaplan, H.

1995 Drugs, crime, and other deviant adaptations: Longitudinal studies. Longitudinal research in the social and behavioral sciences: An interdisciplinary series. New York, NY: Plenum Press. 
Kilpatrick, D. G., Edmunds, C. N. \& Seymour, A. K.

1992 Rape in America: A report to the nation. Arlington, V.A. and Charleston, S.C: National Victim Center and Crime Victims Research and Treatment Center.

Kipke, M. D., Montgomery, S., \& MacKenzie, R. G.

1993 Substance use among youth seen at a community-based health clinic. Journal of Adolescent Health 14, 289-294.

Kipke, M., Simon, T., Montgomery, S., Unger, J., \& Iverson, E.

1997 Homeless youth and their exposure to and involvement in violence while living on the streets. Journal of Adolescent Health, 20. 360-367.

Koopman, C., Rosario, M., \& Rotheram-Borus, M. J.

1994 Alcohol and drug use and sexual behaviors placing runaways at risk for HIV infection. Addictive Behaviors, 19, 95-103.

Kufeldt, K., \& Nimmo, M.

1987 Youth on the street: Abuse and neglect in the eighties. Child Abuse $\mathcal{E} \mathrm{Ne}-$ glect, 11, 531-43.

MacLean, M. G, Paradise, M. J., \& Cauce, A. M.

1999 Substance use and psychological adjustment in homeless adolescents: A test of three models. American Journal of Community Psychology, 27, 405-427.

Maddahian, E., Newcomb, M.D., \& Bentler, P.M.

1988 Risk factors for substance use: Ethnic differences among adolescents. Journal of Substance Abuse, 1, 11-23.

McCormack, A., Janus, M., \& Burgess, A.W.

1986 Runaway youths and sexual victimization: Gender differences in adolescent runaway population. Child Abuse \& Neglect, 10, 387-395.

McMorris, B. J., Tyler, K. A., Whitbeck, L. B., \& Hoyt, D. R.

2002 Familial and "on-the-street" risk factors associated with alcohol use among homeless and runaway adolescents. Journal of Studies on Alcohol, 63, 34-43.

Miller, E. M.

1986 Street women. Philadelphia: Temple University Press.

Patterson, G. R.

1982 Coercive family processes. Eugene, OR: Castilia.

Patterson, G. R., Debaryshe, B. D., \& Ramaey, E.

1989 A development perspective on antisocial behavior. The American Psychologist, 44, 329-335.

Patterson, G. R., Dishion, T. J., \& Bank, L.

1984 Family interaction: A process model of deviancy training. Aggressive Behavior, 10, 235-267.

Peters, S. D.

1988 Child sexual abuse and later psychological problems. In G. E. Wyatt \& G. J. Powell (Eds), Lasting effects of child sexual abuse (pp. 101-1117). Newbury Park, CA: Sage. 
Rohsenow, D. J., Corbett, R., \& Devine, D.

1988 Molested as children: A hidden contribution to substance abuse? Journal of Substance Abuse Treatment, 5, 13-18.

Rotheram-Borus, M. J., Meyer-Bahlburg, H., Koopman, C., Rosario, M., Exner, T. M., Herderson, R., Matthieu, M., \& Gruen, K.S.

1992 Life sexual behaviors among runaway males and females. Journal of Sex Research, 29, 15-29

Rutter, M.

1989 Pathways from childhood to adult life. Journal of Child Psychology and Psychiatry, 30, 23-51.

Sedlak, A. J., \& Broadhurst, D. D.

1996 Third national incidence study of child abuse and neglect. Rockville, MD: U.S. Department of Health and Human Services.

Silbert, M. H., \& Pines, A. M.

1981 Sexual child abuse as an antecedent to prostitution. Child Abuse E Neglect, $5,401-471$.

Simons, R., \& Whitbeck, L.

1991 Sexual abuse as antecedent to prostitution and victimization among adolescent and adult homeless women. Family Issues, 12, 361-379.

Singer, M. I., Petchers, M. K., \& Hussey, D.

1989 The relationship between sexual abuse and substance abuse among psychiatrically hospitalized adolescents. Child Abuse \& Neglect, 13, 319-325.

Stein, J. A., Golding, J. M., Siegel, J. M., Burnam, M. A., \& Sorenson, S. B.

1988 Long-term psychological sequelae of child sexual abuse: The Los Angles epidemiological catchment area study. In G. E. Wyatt \& G. J. Powell (Eds), Lasting effects of child sexual abuse (pp. 135-154). Newbury Park, CA: Sage.

Stiffman A. R., Earls, F., Powell J., \& Robins, L. N.

1987 Correlates of alcohol and illicit drug use in adolescent medical patients. Contemporary Drug Problems, 14, 295-314.

Straus, M. A.

1979 Measuring intrafamily conflict and violence: The conflict tactics (CT) scales. Journal of Marriage and the Family, 41, 75-88.

Tyler, K. A., Hoyt D. R., Whitbeck L. B., \& Cauce, A. M.

2001 The impact of childhood sexual abuse on later sexual victimization among runaway youth. The Journal of Research on Adolescence, 11, 151-176.

Tyler, K. A., Whitbeck L. B., Hoyt D. R., \& Yoder K. A.

2000 Predictors of self-reported sexually transmitted diseases among homeless and runaway adolescents. The Journal of Sex Research, 37 (4), 369-377.

Whitbeck, L.B., \& Hoyt, D.R.

1999 Nowhere to grow: Homeless and runaway adolescents and their families. Hawthorne, NY: Aldinede Gruyter. 
Whitbeck, L. B., Hoyt, D. R., \& Ackley, K.

1999 A risk-amplification model of victimization and depressive symptoms among runaway and homeless adolescents. American Journal of Community Psychology, 27, 273-296.

Whitbeck, L. B., \& Simons, R. L.

1990 Life on the streets: The victimization of runaway and homeless adolescents. Youth \& Society, 22, 108-125.

Whitwire, J. L, \& Harlow, L.

1996 Childhood sexual abuse linked with adult substance use, victimization, and AIDS-risk. AIDS Education and Prevention, 8(1), 44-57.

Widom, C.S., \& Ames, M.A.

1994 Criminal consequences of childhood sexual victimization. Child Abuse \& Neglect, 18, 303-318.

Windle, $\mathrm{M}$.

1989 Substance use and abuse among adolescent runaways: A four-year followup study. Journal of Youth and Adolescence, 18, 31-344. 